\title{
Pulmonary rehabilitation in Italy: professional barriers to overcome
}

\author{
To the Editor:
}

We read with great interest the study on pulmonary rehabilitation by SpRUiT et al. [1] and the accompanying editorial by ROCHESTER et al. [2]. From the starting point of a global view on pulmonary rehabilitation programmes and organisation, the study reports the modalities by which pulmonary rehabilitation is delivered worldwide, showing substantial differences between North America and Europe. As pulmonary physicians working in Italy, we are clearly more interested in the European scenario with the aim to compare our practice with that of other European countries, and to understand the unmet needs and problems in Europe in delivering robust and effective pulmonary rehabilitation programmes.

Overall, many barriers hampering the possibility to undergo pulmonary rehabilitation still exist for Italian patients with chronic disabling respiratory diseases.

There are still a few centres specifically devoted to pulmonary rehabilitation across Italy. In a national study published in 2004 [3], only 53 rehabilitation departments and/or pulmonology units were estimated to warrant availability and accessibility to pulmonary rehabilitation, with more than half of them being located in the north of the country. This seems to be a poor perspective when related to the actual epidemiology of chronic obstructive pulmonary disease patients (2.5 to 3 million in Italy) [4] dealing with the early onset of disability. As well as additional and increasing problems of difficult weaning, pulmonary rehabilitation and physiotherapy in chronic and critically ill patients admitted to acute hospital care [5]. Most of the patients still have their rights to pulmonary rehabilitation denied. There is no information as to whether there have been improvements in the number and distribution of pulmonary rehabilitation centres across the country in the last 10 years; thus, as a consequence, we are now planning an update of that survey.

An additional problem in Italy may be represented by the so called "P factor", namely the physiatrist factor, i.e. doctors specialised in physiatry. Likewise, across Europe these specialists are in charge of and deal with the overall problem of rehabilitation in the healthcare system. Notwithstanding, they traditionally specialise in disabilities associated with musculoskeletal diseases and/or conditions following surgery, with only a very few of them experiencing rehabilitation following neurological conditions such as cerebral stroke. In 2011, the Italian Ministry of Health published a report on rehabilitation [6]. For the first time, this document, approved by an ad hoc committee, recognised not only physiatrists as experts in rehabilitation but also cardiologists, pulmonologist and oncologists, among others. Notwithstanding, and as a compromise, it also reinforced the "P factor" by stating that physiatrists should have overseen all the rehabilitation indications and programmes, including in patients suffering from diseases not within their own specific competence, but leaving space for all 21 national regions to decide independently. As a consequence, regional rules and health policies issued after 2011 are different across Italy, with regions in which pulmonary rehabilitation can and cannot be approved without an evaluation by a physiatrist being the very last stage of the decision. Notably, and in contrast with this behaviour, the international survey by SpRUiT et al. [1] essentially did not find any prominent role for physiatrists in the pulmonary rehabilitation course.

In the past decades, several Italian pulmonologists working in pulmonary rehabilitation have been widely recognised as national leaders and international experts, attending task forces and contributing to research in this field. A quick search in PubMed revealed that in the period of 1970 to date, Italian pulmonologists actively participated in $\sim 5 \%$ of all the published peer-reviewed articles and documents dealing with pulmonary rehabilitation and lung diseases (339 out of 7169), whereas national physiatrists actively participated in $<1.7 \%$ of articles related to rehabilitation and neurological or orthopaedic disorders. Thus, the national group of pulmonologists expert in pulmonary rehabilitation contributed greatly to the development of this discipline as an evidence-based, non-pharmacological treatment for disabled respiratory individuals.

Finally, and in contrast to the organisations in North and South America, in Europe there is still a lack of physiotherapists specifically involved in pulmonary rehabilitation and qualified to deliver programmes to respiratory patients. This has been emphasised in Italy in recent years [7], with the academic qualification of these healthcare professionals being an important aspect of the problem. On the one hand, the overall request to study a degree in physiotherapy is very high in Italy (one student admitted to the university over 
14 requests of admission) [8], on the other hand, the specific qualification of a respiratory physiotherapy does not exist and only post-doctoral courses (masters) can be obtained for this qualification. In addition, during the degree course in physiotherapy, $<10 \%$ of teaching credits are dedicated to cardiopulmonary problems.

Taken together, this situation is calling for national, and hopefully international, action. As pulmonologists and respiratory physiotherapists who have been practicing pulmonary rehabilitation for many years, we are trying to reinforce, at each level, the partnership and the concept that respiratory patients should be optimally treated by experts qualified in the field, in secondary and even primary level care. The generic concept of "undefined" or "unspecialised" rehabilitation as an intervention argued to instead be able to ameliorate any type of disability reinforces the wrong concept of a "one-size-fits-all" type of medicine, likely causing loss of time and resources. A more focused professional approach in the rehabilitation field, recognising the specificity of pulmonary rehabilitation and leaving the responsibility of it to pulmonologists, is the way to allocate resources that are able to ameliorate the condition in disabled respiratory patients.

O @ERSpublications

Pulmonary rehabilitation requires specific competence and skill, must be a matter for pulmonologists http://ow.ly/xC6tD

Bruno Balbi ${ }^{1}$, Nicolino Ambrosino ${ }^{2}$, Marta Lazzeri $^{3}$, Franco Pasqua ${ }^{4}$, Michele Vitacca $^{5}$ and Enrico Clini ${ }^{6}$

${ }^{1}$ Pulmonary Rehabilitation, Fondazione Maugeri IRCCS, Veruno, Italy. ${ }^{2}$ Pulmonary Rehabilitation and Weaning, Auxilium Vitae Rehabilitation Centre, Volterra, Italy. ${ }^{3}$ Associazione Riabilitatori della Insufficienza Respiratoria (ARIR), Milan, Italy. ${ }^{4}$ Pulmonary Medicine and Rehabilitation, San Raffaele Hospital, Montecompatri, Italy. ${ }^{5}$ Pulmonary Rehabilitation, Fondazione Maugeri IRCCS, Lumezzane, Italy. ${ }^{6}$ Dept of Medical and Surgical Sciences, Ospedale Villa Pineta, University of Modena Reggio Emilia, Modena, Italy.

Correspondence: Enrico M. Clini, University of Modena, Villa Pineta Rehabilitation Hospital, Via Gaiato 127, Modena, Italy. E-mail: enrico.clini@unimore.it

Received: May 292014 | Accepted: May 302014

Conflict of interest: None declared.

\section{References}

1 Spruit MA, Pitta F, Garvey C, et al. Differences in content and organisational aspects of pulmonary rehabilitation programmes. Eur Respir J 2014; 43: 1326-1337.

2 Rochester CL, Spanevello A. Heterogeneity of pulmonary rehabilitation: like apples and oranges - both healthy fruit. Eur Respir J 2014; 43: 1223-1226.

3 Foglio K, Murgia A, Ambrosino N. Application of respiratory rehabilitation programmes in Italy. Second investigation survey by the AIPO Rehabilitation Study Group. Rass Patol App Respir 2004; 19: 53-61.

4 Age.Na.S. BPCO.Linee guida nazionali di riferimento per la prevenzione e la terapia. Broncopneumopatia Cronica Ostruttiva. www.pneumonet.it/scientifico/editoriali/linee_guida_BPCO_2010/BPCO.pdf Date last updated: June 2010. Date last accessed: May 2014.

5 Ambrosino N, Venturelli E, Vagheggini G, et al. Rehabilitation, weaning and physical therapy strategies in chronic critically ill patients. Eur Respir J 2012; 39: 487-492.

6 Quaderni del Ministero della Salute. La centralità della Persona in riabilitazione: nuovi modelli organizzativi e gestionali. No.8 March-April 2011. www.quadernidellasalute.it/archivio-quaderni/8-marzo-aprile-2011.php Date last accessed: May 2014.

7 Clini E, Lazzeri M, Lusuardi M. Respiratory therapist: urgent need for a professional profile. Rass Patol App Respir 2004; 19: 185-186.

8 Mastrillo A. Lauree triennali delle professioni sanitarie. Dati sull'accesso ai corsi e programmazione posti nell' A.A. 2013-14. http://cplps.altervista.org/blog/wp-content/uploads/2011/07/Report-mastrillo-7-dic.2013-x-Oss..pdf Date last updated: December 2013. Date last accessed: May 2014. 